\title{
Course and outcome of patients in vegetative state of nontraumatic aetiology
}

\author{
Leon Sazbon, Fanny Zagreba, Jacob Ronen, Pablo Solzi, Hanan Costeff
}

\begin{abstract}
A follow up study is reported of 100 consecutive unconscious patients admitted to an intensive care coma facility with a history of 30 days or more of unconsciousness of nontraumatic cause. Twenty recovered consciousness, all within 5 months of injury. 31 of the remaining patients died within 6 months following injury, while 49 continued unconscious until death. The mean life expectancy of these 49 was $26-34$ months from that time. All 20 patients who recovered awareness continued to suffer from major disability. The prognosis for life or death and for recovery or not of consciousness was not significantly correlated with age or aetiology of the vegetative state. Among those who recovered consciousness, the younger patients showed somewhat better results in three parameters of function: locomotion, ADL and day-placement, but not in cognition, behaviour or speech accuracy and fluency. The overall results for these nontraumatic patients with postcomatose unawareness are clearly worse than those for patients with a similar period of unconsciousness following craniocerebral trauma.
\end{abstract}

$(\mathcal{F}$ Neurol Neurosurg Psychiatry 1993;56:407-409)

The development of medical facilities for prolonged intensive care of the unconscious patient has resulted in the growth of a previously negligible medical problem, namely the patient who remains unconscious but alive. This problem includes two major pathogenetic subtypes, traumatic and non-traumatic, which differ greatly in their course and prognosis. Over the past decade numerous series have been published dealing with the prognosis of patients with persistent vegetative state or "Post-coma unawareness" (PCU) ${ }^{1}$ patients. However, these studies have mostly dealt either with post-traumatic unconsciousness $^{2-5}$ or with patients whose prolonged duration of post-anoxic unconsciousness is defined as 24 hours or more. ${ }^{6-9}$ The specific problem of the patient who remains unaware for weeks following nontraumatic coma has not yet been addressed.

We have followed 100 consecutive patients admitted to our unit with post-anoxic unconsciousness of at least 30 days duration.

\section{Materials and methods}

The study group includes the first 100 patients with PCU state lasting at least 30 days following anoxia who were admitted to our intensive care coma unit during 1974-87. They included 63 males and 37 females. The age range was 2-80 years, with a mean of 38 . Sixteen patients were aged 2-16, 47 were aged $17-45$, and 37 were aged 46 years or more. The aetiology of post-coma unawareness (PCU) was cardiac arrest or respiratory failure in 34 cases, complications of anaesthesia and/or neurosurgery in 34, stroke in 15, encephalitis in 8 and various other causes in 9 .

Twenty of the patients recovered consciousness, as defined by establishment of meaningful verbal or visual-motor communicative contact with their environment. They were discharged after a median period of 328 days of inpatient rehabilitation (range 55-1254 days). Their function was assessed in a number of areas. Locomotor function, independence in activities of daily living (ADL), cognition, communication and behaviour were assessed semi-quantitatively by a multidisciplinary team at discharge. The patients' overall occupational placement was assessed at outpatient follow up which was performed at least a year after discharge. This was classified in three categories: normal employment or school setting, sheltered dayplacement, or round-the-clock nursing care.

The remaining 80 patients failed to recover consciousness, and 68 of them died before the final follow up, which was at least 72 months after onset of unconsciousness. During this period five living unconscious patients were lost to follow up following their transfer to other medical facilities. Seven patients remain in hospital in our centre in a state of post coma unawareness.

Most of the statistical analyses performed were those suited to ordered outcome categories. These included the Mann-Whitney test when two groups were compared, and the Spearman rank correlation when three or more ordered groups were compared.

\section{Results}

Table 1 presents the outcomes of each of the various aetiologies of PCU. When the outcome was classified as conscious, unconscious or dead, there was no significant difference among them in outcome. Similarly, there was no significant association between outcome and age (table 2).

All 20 patients in this series who recovered consciousness did so within five months of 
Table 1 Aetiology and late outcome in 100 cases of prolonged ( $\geq 1$ month) nontraumatic PCU

\begin{tabular}{lllrr}
\hline Outcome & Conscious & Unconscious & Dead & Total \\
\hline Aetiology: & & & & \\
Cardiorespiratory & & & & \\
Disease: & 5 & 5 & 24 & 34 \\
Stroke: & 7 & 1 & 26 & 34 \\
Aneasthesia: & 4 & 2 & 9 & 15 \\
Encephalitis: & 1 & 2 & 5 & 8 \\
Other: & 3 & 2 & 4 & 9 \\
Total: & 20 & 12 & 68 & 100 \\
\hline
\end{tabular}

$\chi^{2}=7.61 \mathrm{DF}=8 \mathrm{p} \gg 0.1$.

Table 2 Age and late outcome in 100 cases of prolonged $(\geq 1$ month) nontraumatic $P C U$

\begin{tabular}{lcccc}
\hline Age/Outcome & Conscious & Unconscious & Dead & Total \\
\hline $2-16$ & 2 & 3 & 11 & 16 \\
$17-45$ & 11 & 6 & 30 & 47 \\
$>45$ & 7 & 3 & 27 & 37 \\
Total & 20 & 12 & 68 & 100 \\
\hline
\end{tabular}

$r_{\text {SPEARMAN }}=-0.04 \mathrm{t}=0.41 \mathrm{DF}=98 \mathrm{p} \gg 0.1$.

losing it. As seen in table 3, by six months after onset a further 31 had died, while 49 remained unconscious for the remainder of their lives. Since there was no recovery after the first six months, we calculated life expectancy for these 49 patients from that point in time. Life table methods gave a median life expectancy of 12 months and a mean of at least 26 months after the loss of all hope for recovery. As it is rare in our experience for an unconscious patient to survive more than 10 years, we may assume that this will be the upper limit of survival of our seven patients who are still alive; on this assumption, the upper bound of estimate for mean life expectancy in this group would be 34 months, and the most probable estimate for mean life expectancy would be the midpoint between the upper and lower bounds of estimate, that is, 30 months after loss of hope for recovery.

All of the 20 patients who recovered consciousness after being unconscious for at least a month remained with major disability. Seventeen of them showed tetraparesis, 19 of them had significant cognitive deficits, 15 were dysphasic, and 13 had behaviour problems. Of the 18 for whom follow up data were available regarding occupational placement, only one was gainfully employed, while three were in sheltered day-placement conditions and 14 were in round-the-clock nursing care.

Among those patients who recovered consciousness, age at injury was significantly associated with some but not all of the outcome parameters. The younger patients achieved more independence in ambulation than the older ones. Six of the seven patients over the age of 45 remained bedridden, while

Table 3 Late outcome in 100 cases of prolonged ( $\geq 1$ month) nontraumatic PCU, by duration of follow up since onset

\begin{tabular}{lrrrrrrrrrrr}
\hline Follow up in months: & 1 & 3 & 6 & 9 & 12 & 18 & 24 & 30 & 36 & 48 & 72 \\
\hline Conscious & 0 & 12 & 20 & 20 & 20 & 20 & 20 & 20 & 20 & 20 & 20 \\
Unconscious & 100 & 73 & 49 & 38 & 33 & 23 & 20 & 20 & 18 & 12 & 7 \\
Dead & 0 & 15 & 31 & 41 & 46 & 56 & 59 & 59 & 60 & 64 & 68 \\
Untraced & 0 & 0 & 0 & 1 & 1 & 1 & 1 & 1 & 2 & 4 & 5 \\
\hline
\end{tabular}

These statistics are cumulative. All patients who once recovered consciousness are tabulated from then on as conscious, regardless of the time of follow up. One of these conscious patients died from sepsis after recovering consciousness, but is not included among the deaths in the table. the seventh was restricted to a wheelchair; 6 of the 11 patients aged 17-45 were bedridden, 4 were wheelchair-bound and one achieved assisted walking. By contrast both of the children attained at least partially independent walking ( $\mathrm{p} \ll 0.01)$.

The younger patients also attained a greater degree of independence in activities of daily living. The two children attained complete independence in this area, compared with one of 11 young adults and none of the 7 older patients $(p<0.02)$. Similarly, the late occupational placement of the younger patients was significantly better (although not good).

All of the seven older patients remained in nursing care, compared with none of the patients aged $\leq 16$ and seven of the nine young adults for whom placement data were available $(\mathrm{p} \gg 0.01)$.

Despite their relative advantage, even the younger patients remained quite handicapped, although less so than the older ones. By contrast, no significant association was seen between age and dysphasia, cognitive deficits or neurological findings.

Among the 20 patients who recovered awareness, the duration of unconsciousness was not significantly associated with the eventual functional level. Among the five who were unconscious less than 60 days, two could be discharged home and three were transferred to nursing units, while among the 15 who were unconsciousness $61-150$ days 4 were sent home $(p \gg 0 \cdot 1)$.

\section{Discussion}

Our salient findings in patients with nontraumatic PCU of over 30 days duration were: 1 ) By 6 months after onset $20 \%$ had recovered consciousness and another $31 \%$ were dead. The other $49 \%$ remained permanently unconscious. 2) The cause of PCU and the age at injury showed no significant correlation with the above prognosis. 3) No patient regained awareness after unconsciousness of more than 5 months duration. 4) Among those patients who remained unconscious after 6 months, mean additional life expectancy was estimated as 26-34 months, and median additional life expectancy was 12 months. 5) Among those who regained consciousness, several parameters of quality of survival were significantly correlated with age at injury. Younger patients showed somewhat better locomotor status, independence in ADL and day placement. Age was not correlated significantly with cognitive status, dysarthria or behaviour disturbances. 6) There was no significant difference in functional outcome between patients who recovered awareness after 30-60 days of unconsciousness and those who recovered after 61-150 days.

As no comparable series of patients with post-anoxic unconsciousness of over a month's duration has been previously published, it is difficult to compare our findings 1,2 and 4 with other studies. Our third finding can, however, be taken as a rule to which there are already published exceptions, since 
single cases have been reported of recovery of consciousness after 6-18 months. ${ }^{1011}$ These exceptions would indicate that our data may be taken as a basis for statistical expectations, but not as an absolute denial of the possibility of later recovery of awareness. It should be added, however, that the few published cases of very late recovery after nontraumatic PCU remained very severely disabled.

The influence of age on prognosis of nontraumatic PCU has been a subject of controversy. A previous series from this institution found that 13 patients aged $\geq 25$ had a better functional prognosis than did 19 patients aged $>25 . .^{12}$ However, only nine of these patients were unconscious for more than 4 weeks. Two other series ${ }^{1314}$ failed to find a correlation between age and functional prognosis, but these also included mainly patients with shorter periods of unconsciousness than those of our study. A similar controversy exists as to whether age is correlated with outcome in post-traumatic coma, ${ }^{15-23}$ but mostly the published studies of traumatic as well as nontraumatic injury have dealt with considerably shorter periods of unconsciousness than those of the present series. Our findings support an intermediate view of the effect of age on prognosis, given the fact of prolonged post-anoxic unconsciousness. Under these circumstances, age seems to have no association with likelihood of death or recovery of consciousness; among those who recover consciousness, the functional status of the younger patients is significantly, but not dramatically, less bad.

Our finding that duration of unconsciousness is not correlated with functional outcome may seem paradoxical at first glance, especially when contrasted to the findings of other studies. ${ }^{36}$ However, the paradox is more apparent than real. Given the fact of at least 30 days of unconsciousness, all these patients had suffered an extremely severe degree of brain damage, which rendered relatively negligible any further differences in duration of unconsciousness. It is obvious that if the full range of possible durations of unconsciousness had been included, this parameter would have been correlated with outcome.

Our data show that the prognosis of nontraumatic PCU is much worse than that of the same duration of unconsciousness following trauma. The overall results are inferior to those reported by us for trauma, ${ }^{21516}$ and the period during which recovery of consciousness is likely is shorter. ${ }^{12}$ This difference in prognosis between trauma and anoxia parallels that reported for shorter periods of unconsciousness. ${ }^{12} 1724$ These differences in outcome may be related to differences in pathology. Ischaemia and anoxia cause cortical damage, cortical disconnection, laminar necrosis and/or diffuse demyelination, ${ }^{3915}$ while trauma tends to cause diffuse axonal injury due to shearing forces, and microhaemorrhages in the border zone between white and grey matter, with relative sparing of the cerebral cortex. ${ }^{25}$

The surprisingly long (26-34 months) additional life expectancy of patients who have already been unconscious for 6 months, and who have essentially no hope of ever recovering consciousness, indicates that this is a significantly large new category of need for medical and nursing care. We have followed 49 such patients over a 14 year period, out of a total Israeli population of 4-5 million. This implies an incidence of approximately 0.75 per million population per year. Since many additional such patients are in hospital in other facilities, the real extent of this problem is considerably greater. The mean economic cost of each of these patients is that of almost 1000 days of hospital stay in an intensive care facility. The human cost to their families and caretakers is incalculable, but no less important.

1 Sazbon L, Groswasser Z. Prolonged coma, vegetative state, postcomatose unawareness: semantics or bette understanding? Brain Injury 1991;5:1-2.

2 Sazbon L, Groswasser Z. Outcome in 134 patients with prolonged posttraumatic unawareness. Part I. Parameters determining late recovery of consciousness. f Neurosurg 1990;72:75-80.

3 Higashi K, Sakata Y, Hatano $M$, et al. Epidemiological studies on patients with persistent vegetative state. $\mathcal{f}$ Neurol Neurosurg Psychiatry 1977;40:876-85.

4 Braakman R, Jennett WB, Minderhoud JM. Prognosis of the posttraumatic vegetative state. Acta Neurochirurg the posttrauma

5 Bricolo A, Turazzi S, Feriotti G. Prolonged posttraumatic unconsciousness. Therapeutic assets and liabilities. $f$ Neurosurg 1980;52:625-34.

6 Levy DE, Caronna JJ, Singer $\mathrm{BH}$, et al. Predicting outcome from hypoxic-ischemic coma. $\mathscr{f} A M A 1985$ 253:1420-6.

7 Sacco RL, VanGool R, Mohr JP, et al. Nontraumatic coma. Glasgow coma score and coma etiology as predictors of 2-week outcome. Arch Neurol 1990;47:1181-4.

8 Yarnell PHR. Neurological outcome of prolonged coma survivors of out-of-hospital cardiac arrest. Stroke 1976;7:279-82.

9 Dougherty JH, Rawlinson DG, Levy DE, et al. Hypoxicischemic brain injury and the vegetative state. Clinical ischemic brain injury and the vegetative state. Clinical

10 Bates D, Caronna JJ, Cartlidge EF, et al. A prospective study of nontrumatic coma. Methods and results in 310
stum patients. Ann Neurol 1977;2:211-20.

11 Rosenberg GA, Johnson SF, Brenner RP. Recovery of cognition after prolonged vegetative state. Ann Neurol 1977;2:167-8

12 Groswasser Z, Cohen M, Costeff $\mathrm{H}$. Rehabilitation outcome after anoxic brain damage. Arch Phys Med Rehab 1989;70:186-8.

13 Levy DE, Knill-Jones RP, Plum F. The vegetative state and its prognosis following nontraumatic coma. Ann NY Acad Sciences 1978;315:293-304.

14 Tweed WA, Thomassen A, Wernberg M. Prognosis after cardiac arrest based on age and duration of coma. Can Med Assoc F 1982;126:1058-9.

15 Sazbon L. Prolonged coma. Prog Clin Neurosci 1985;2:65-81.

16 Groswasser Z, Sazbon L. Outcome in 134 patients with prolonged postrraumatic unawareness. Part 2. Functional outcome of 72 patients recovering consciousness. F Neurosurg 1990;72:81-4

17 Najenson T, Mendelson L, Schechter I, et al. Rehabilitation after severe brain injury. Scand $\mathcal{f}$ Rehab Med 1974;6:5-14.

18 H Costeff, Z Groswasser, R Goldstein Long-term Followup Review of 31 Children with Severe Closed-head Trauma. F Neurosurg 1990;73:684-7.

19 Mahoney WJ, D'Souza BJ, Haller JA, et al. Long-term outcome of children with severe head trauma and prolonged coma. Pediatrics 1983;71:756-62.

20 Luerssen TG, Klauber MR, Marshall LF: Outcome from head injury related to patient's age. $\mathcal{f}$ Neurosurg 1988;68:409-16.

21 Facco E, Zuccarello M, Pittoni G, et al. Early outcome prediction in severe head injury in childhood: prediction in severe head injury in childhood: comparison between

22 Kriel RL, Krach LE, Sheehan M. Pediatric closed head injury: outcome following prolonged unconsciousness
ing injury: outcome following prolonged unce

23 Bruce DA, Schut L, Bruno LA, et al. Outcome following severe head injuries in children. $f$ Neurosurg 1978 48:679-88.

24 Sazbon L, Groswasser $\mathrm{Z}$. Time related sequelae of TB patients with prolonged postcomatose unawareness (PC-U) state. Brain Injury 1991;5:3-8.

25 Strich SJ. Diffuse degeneration of the cerebral white matter in severe dementia following severe head injury. f Neurol Neurosurg Psychiat 1956;19:163-185. 